\title{
Assessment as Action Research: Bridging Academic Scholarship and Everyday Practice
}

\section{Kara J. Malenfant, Lisa Janicke Hinchliffe, and Debra Gilchrist}

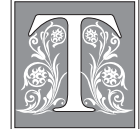

his special issue of College and Research Libraries proudly features a selection of action research studies by participants of the ACRL program "Assessment in Action: Academic Libraries and Student Success" (AiA). Just over 200 institutions have participated in the AiA program, with a librarian from each leading a campus team in developing and implementing an action learning project that examines the impact of the library on student success and contributes to assessment activities on campus. The AiA approach to action learning projects is described to potential applicants as follows:

The AiA program focuses on assessment, which we believe is rooted in identifying important questions about student learning/success, designing assessments that yield information about library contributions, and taking action based on what has been uncovered. All action learning projects should go beyond use and satisfaction and examine questions of impact and outcomes. For some teams the projects may be a first step in examining what impact the library may have on student learning and success. Work will represent an initial step or pilot project through which teams will learn more, move to action, and take a deeper look at a particular area of interest. Teams undertaking "seed" projects of this type will begin an effort that will result in a longer term commitment on campus in the future. For other teams, a previous assessment activity may have raised questions for further exploration. Therefore, some projects will move beyond describing what type of impact is occurring (or not occurring) and take a deeper look into how the library creates an impact on students. Not all projects will demonstrate that there is in fact a library impact and key criteria for "success" will be different. Developing and implementing a project as part of the AiA program will engender learning, spur action, and build capacity for continued work in this area. ${ }^{1}$

Kara J. Malenfant is Senior Strategist for Special Initiatives at the Association of College and Research Libraries, e-mail: kmalenfant@ala.org; Lisa Janicke Hinchliffe is Professor, University Library and Coordinator for Information Literacy Services and Instruction at the University of Illinois at Urbana-Champaign, e-mail: ljanicke@illinois.edu; Debra Gilchrist is Vice President for Learning and Student Success at Pierce College, e-mail: dgilchri@pierce.ctc.edu. (C) 2016 Kara J. Malenfant, Lisa Janicke Hinchliffe, and Debra Gilchrist, Attribution-NonCommercial 3.0 (http://creativecommons.org/licenses/by-nc/3.0/) CC BY-NC 3.0 
Over the course of the 14-month long AiA program, the librarian team leaders are supported in this work by a professional development program with sequenced learning events and activities at key junctures. The activities were strategically designed by AiA facilitators to follow the natural arc of the assessment process while also building a strong community of practice. ${ }^{2}$ At the conclusion of their projects, all AiA team leaders provide descriptive project reports and present posters, which are disseminated publicly online (https://apply.ala.org/aia). The third year of AiA is still underway, and team leaders will be presenting posters in June 2016 at the ALA Annual Conference in Orlando with online reports available in the fall.

In developing AiA, we did not expect that all projects would yield generalizable results, as you would expect of findings from social science research conducted from a positivist perspective, or determine meaning or relevance, as in qualitative social science research methods; however, many projects are replicable at other libraries or contain elements that are transferable to other settings. We encourage you to explore the online collection and to read the two ACRL reports, which synthesize findings from the AiA projects to date. ${ }^{3}$ Furthermore, a recently published ACRL casebook showcases short reflections by first-year AiA team leaders on the inquiry methods they used in their assessment projects. ${ }^{4}$

To further shine a light on the scholarly work emerging from AiA participants, we put forth a call for proposals for this special issue of $C \mathcal{E} R L$ and were very pleased to receive 24 proposals, from which we accepted seven; this acceptance rate of 30 percent is in keeping with $C E R L$ 's typical selective standard. As context for the studies in this special issue, this introductory essay provides a basic overview to action research, which is

a participatory, democratic process concerned with developing practical knowing in the pursuit of worthwhile human purposes, grounded in a participatory worldview which we believe is emerging at this historical moment. It seeks to bring together action and reflection, theory and practice, in participation with others, in the pursuit of practical solutions to issues of pressing concern to people, and more generally the flourishing of individual persons and their communities. ${ }^{5}$

As is typical of research approaches that are becoming part of the academic mainstream, confusion and debate exist about what action research is and to what standards it should be held. This special issue aims to help CERL readers learn more about action research as an approach to scholarship and showcase examples of fruitful action research studies undertaken by AiA teams.

The scholarship of action research recognizes important insights that come from practice to theory. It is distinguished from other research forms not by how it is done but why. Action research extends both the degree of change intended and the degree of community involvement over other community-based research forms of traditional fieldwork or applied research. Action research is conducted with and by the participants; action research does not require distance from participants as "subjects."

The research studies in this issue have used many types of empirical research designs and a wide variety of methods and tools, whether qualitative, quantitative, or a mix of both (e.g., correlational, descriptive, ethnography, phenomenology, focus groups, interviews, surveys, rubrics, etc.). Where a traditional research study may seek to draw conclusions about the nature of the world (i.e., building theory), action research aims to address worthwhile and practical concerns in a real-life setting by taking up urgent problems facing communities at that time.

Among its hallmarks, action research is participative and democratic, conducted with and by participants, involving them in the research process. Depending on the 
focus of a project, AiA participants may have been students themselves, disciplinary faculty members, library colleagues, or other academic professionals on campus. Because participants have a voice, action research is an emergent process-iterative rather than linear - and the researcher does not specify a research design at the onset. Since initial data analysis may change the research question itself, action research can feel messy and unpredictable. This responsiveness has strength through the potential of action research to yield powerful results that matter in the real world.

Since the purpose of action research is to inform practice, it starts from a perspective of problem solving by asking, "What, if anything, should change?"7 The principal standard for appraising action research is likewise quite practical-does it provide information that helps inform decision making? Generally, when evaluating or appraising any kind of empirical research study, a reader uses criteria of both merit (as relevant for the chosen method-e.g., tight design, variables well controlled, instrumentation elegant, sample representation, etc.) and worth (i.e., usable results, applicability to specific setting, etc.). Action research can, and should, excel at both.

Like other empirical research, the studies in this issue relied on direct observations or experiences to record new data. In addition to meeting the general criteria for any empirical research, McMillan and Wergin advise action researchers to be diplomatic and sensitive, as the consequences of findings from action research often have political and ethical implications for practice. Their results may be used to make value judgments about what is effective or not. ${ }^{8}$ Hale advises those engaged in newer forms of research, such as action research, to assertively report the ways in which they scrupulously followed the method(s) they chose. ${ }^{9}$

The authors in this issue represent a wide variety of types of institutions and regions. We were especially pleased that every article is co-authored, as collaboration is key to the success of action research. The studies looked at a range of problem statements related to student learning and success as well as using many different methods (often mixed) and sources of data. Some authors participated in the first year of AiA and completed their projects in 2014 while others are from the second year and completed their projects in 2015. By virtue of participation in AiA, these authors are quite skilled at being supportive of each other and providing critical friend feedback. They chose to participate in a peer feedback process over the fall while they were revising their manuscripts. In giving and receiving input, serving as external readers and being supportive sounding boards during the writing process, they extended the AiA community of practice that has developed.

The field of action research is hugely varied with all kinds of choices to be made in conducting a study with this orientation. The studies in this issue exemplify the following five broad features Reason and Bradbury describe as characterizing action research. ${ }^{10}$

The practical issue of pressing concern in the work by the Illinois Institute of Technology was to understand the library's contribution to the university strategy of improving student retention to 90 percent, while remaining committed to the provision of excellent service to its students. Similarly, the team at the University of Alberta engaged a pressing campus concern-engagement and success of self-identified Aboriginal students through a formal connection with a Personal Librarian.

The study by St. Mary's College of Maryland shows a deep concern with the flourishing of people and communities through the librarians' commitment to first-year student success. By developing deeper collaboration with teaching faculty and assessing student learning in the first-year seminar for the first time since its inception, the AiA team led the way on campus through modeling how to design and carry out robust and meaningful assessment. 
To understand action research as an emergent developmental form, see the study by University of California, Merced, which featured an evolving quantitative design (to more tightly bound the group of students to be examined) and emerging qualitative design (while scoring student reflective papers with a rubric, librarians realized that coding some answers could further help them make meaning). Similarly, at Anne Arundel Community College, action research was developmental and supported an effective community of inquiry that spanned the entire college. Because the AiA team's preliminary data showed that graduating students regularly scored below proficient levels, information literacy was the theme of their 2015 Summer Institute, a day-long faculty professional development opportunity.

The study by Grinnell College illustrates action research as democratic by involving students and faculty in the process of rating student work. A preliminary result of this mixed-methods study has been for librarians to emphasize in their teaching concepts such as source evaluation, variety, and contribution to a research project over skills like database searching.

The feature of knowledge-in-action is apparent at Utah State, where the purpose of decision making and the standard of usefulness are very clear. As a result of what they learned in the AiA project, the librarians are offering online course-integrated conference sessions, incorporating flipped learning so that in-class time is devoted to active learning exercises on synthesis, and influencing other courses to target for integrating library instruction into programs and departments.

This introductory essay demonstrates that action research has a vital role in evidenceinformed practice in academic libraries. Scholarly projects like the ones described in this special issue can support the development of a culture of evidence-informed decision making. Through the articles in this issue, readers can come to a deeper understanding of action research as a productive, appropriate, and rigorous way of knowing and generating knowledge. Action research studies, such as these, are effective means of building a profession's ways of knowing, nurturing a community of practice, and generating legitimate and rigorous scholarship. We invite you to learn, through the thoughtful contributions of these authors, the value of this research approach as well as their results.

\section{Notes}

1. Read more about the Assessment in Action program online at http://www.ala.org/acrl/ AiA. The AiA program, a cornerstone of ACRL's Value of Academic Libraries initiative, is made possible by the Institute of Museum and Library Services and carried out in partnership with the Association for Institutional Research and the Association of Public and Land-grant Universities.

2. AiA Facilitators: April Cunningham, Carrie Donovan, Debra Gilchrist, Lisa Janicke Hinchliffe, Eric Resnis, John Watts.

3. Karen Brown and Kara J. Malenfant, Academic Library Contributions to Student Success: Documented Practices from the Field (Chicago: ACRL, 2015), http://www.ala.org/acrl/sites/ala.org. acrl/files/content/issues/value/contributions_report.pdf. A synthesis of the second year projects will be available in early 2016.

4. Eric Ackermann, Putting Assessment into Action: Selected Projects from the First Cohort of the Assessment in Action Grant, (Chicago: ACRL, 2016).

5. Peter Reason and Hilary Bradbury, Handbook of Action Research (London: SAGE Publications, 2006), 1.

6. Richard A. Couto, Sarah Hippensteel Hall, and Marti Goetz, "Leading Change in the Community Context," in Leading Change in Multiple Contexts, ed. Gill R. Hickman, 119-49 (Thousand Oaks, CA: Sage, 2009).

7. James H. McMillan and Jon F. Wergin, Understanding and Evaluating Educational Research. 3rd ed. (Upper Saddle River, NJ: Pearson, 2006), 164.

8. Ibid., 164-65.

9. Charles R. Hale, Engaging Contradictions: Theory, Politics, and Methods of Activist Scholarship (Berkeley: University of California Press, 2008).

10. Reason and Bradbury, Handbook of Action Research, 2. 